\title{
MUDANÇA DE CONCEPÇÃO SOBRE A FORMAÇÃO A DISTÂNCIA: A VISÃO DE ESTUDANTES DO PROJETO PEAD
}

\author{
Celi Lutz, ESPEAD - UFRGS \\ celilutz@gmail.com \\ Rosane Aragón, FACED - UFRGS \\ rosane.aragon@ufrgs.br
}

Resumo: o presente artigo apresenta uma investigação sobre as expectativas de um grupo de professoras-alunas do Curso de Graduação - Licenciatura em Pedagogia na modalidade a distância (PEAD/UFRGS), levantando as suas ideias iniciais sobre a Educação a Distância (EAD) e, mais especificamente, sobre o PEAD e como essas foram se transformando no decorrer do mesmo. O estudo foi realizado a partir de uma amostra de $20 \%$ das alunas de um dos polos do curso. A coleta de dados foi realizada a partir de leituras de registros textuais, além de entrevistas presenciais para complementação dos dados. O tratamento dos dados enfocou: (1) as concepções das professoras-alunas relativas a EAD e as suas expectativas em relação ao curso no seu início; (2) as concepções atuais e as possíveis mudanças das expectativas iniciais ao longo do curso. O estudo evidenciou que as professoras-alunas participantes da pesquisa tiveram as suas expectativas superadas positivamente. Os resultados da pesquisa apontaram para o fato de que as professoras-alunas, gradualmente, tomaram consciência do curso e consideraram que o PEAD efetivou o modelo de aprendizagem em rede na perspectiva de superar as fragmentações e dicotomias entre o projeto pedagógico e as práticas realizadas.

Palavras-chave: Formação de professores, Educação a Distância, Projeto Pedagógico.

\section{CONCEPTION CHANGE ABOUT DISTANCE FORMATION: THE VIEWPOINT OF PEAD PROJECT STUDENTS}

\begin{abstract}
This paper presents an investigation into the expectations of a group of students from the a Licenciature Course in Pedagogy in distance mode (PEAD / UFRGS), bringing their initial conceptions about the distance education modality and, more specifically, about the Project PEAD and how these conceptions were transformed during the same. The study was conducted from a sample of $20 \%$ of the students of one of the support units of the course (support pole). Data collection was performed from readings of textual records, and personal interviews to supplement the data. Data analysis focused on: (1) the conceptions of students on education in the distance mode and their expectations about the course at its beginning, (2) the current conceptions and possible changes of initial expectations throughout the course. The study showed that participants' expectations were surpassed positively. The research results pointed to the fact that students gradually became aware of the design of the course and felt that the PEAD actualized the model networked learning from the perspective of overcoming the fragmentation and dichotomies between the pedagogical design and the practices.
\end{abstract}

Keywords: Teacher education, Distance Education, Pedagogic Design. 


\section{Introdução}

Com a aprovação da Nova Lei de Diretrizes e Bases da Educação Nacional (LDB n ${ }^{\circ}$ 9.394/1996), fica reafirmada no Brasil a necessidade de (re) pensar a formação de professores, principalmente de docentes com atuação nos primeiros anos da Educação Básica, que lecionam sem possuir formação em nível superior.

Nesse panorama de incentivo a formação de professores, a educação a distância (EAD) tem encontrado uma grande expansão, notadamente no final da década de 90 e nos anos seguintes, com a criação de sistemas cooperados ou de redes ${ }^{1}$ e, principalmente, com as iniciativas do Programa Pró-Licenciatura ${ }^{2}$ e a Universidade Aberta do Brasil (1995).

Conforme Prado e Almeida (2009, p. 66), mesmo havendo um consenso sobre a necessidade da formação continuada, o uso da EAD nessa formação pode ocorrer segundo diferentes concepções pedagógicas. Pode-se destacar uma série de possibilidades que são decorrentes de distintas concepções de ensino e de aprendizagem e que determinam o design de um curso, desde a ideia de formação de massa (broadcast) até as abordagens que enfocam as interações e construções de conhecimento.

Ainda que grande parte das pesquisas em EAD aponte para a necessidade de reformulação dos modelos de ensino de massa e assinale reformulações na direção de uma formação reflexiva e de reconstrução das práticas pedagógicas, observa-se um descompasso entre essas ideias e as concepções e práticas desenvolvidas nas formações de professores.

Segundo Oliveira (2002 apud PRETTI, 2005, p. 34), na análise dos projetos pedagógicos de cursos em EAD são visíveis as contradições entre os discursos dos projetos e as suas implementações. Os pressupostos são dialógicos e de interação, enquanto as ações pedagógicas enquadram-se mais em modelos do tipo fordista, de massa, sem uma identidade regional ou local.

Essas constatações, aliadas aos preconceitos em relação à modalidade a distância, têm colocado em dúvida a qualidade das formações e criado uma "imagem" da EAD como política compensatória e/ou como forma de baratear e aligeirar a formação.

Em resposta à busca de alternativas para expandir e qualificar a formação de professores, a Universidade Federal do Rio Grande do Sul (UFRGS) ofereceu, em 2006, seu primeiro curso de graduação para formação de professores na modalidade EAD. O Curso de Graduação em Pedagogia- Licenciatura (PEAD) foi ofertado, em sua primeira edição, visando atender a 400 professoras-alunas ${ }^{3}$ em cinco polos de apoio, sediados nos municípios de Alvorada, Gravataí, São Leopoldo, Sapiranga e Três Cachoeiras.

É notório que a concepção e as expectativas dos participantes de um curso têm fortes influências sobre os seus comportamentos. Tendo em vista o pioneirismo do PEAD na UFRGS e a novidade que esta modalidade de formação representa para as professoras-alunas, entendemos a necessidade de acompanhar e analisar as suas percepções para que tivéssemos maior conhecimento na (re)elaboração de propostas pedagógicas ao longo do curso. Além disso, consideramos muito importante para a avaliação do formato de EAD adotado, conhecer as mudanças que ocorreram nessas concepções originadas durante o desenvolvimento do curso. É possível estabelecer uma relação entre as mudanças e a proposta do curso, podendo contribuir, assim, para a sugestão de novos cursos e o aprimoramento dos modelos de EAD.

Nesta perspectiva, o estudo aqui apresentado tem como objetivo investigar as expectativas de um grupo de professoras-alunas do PEAD (Polo de Sapiranga), no 
início do curso, e como essas foram se transformando no decorrer do mesmo, considerando-se as mudanças nas suas concepções sobre EAD. No texto a seguir, apresentamos um quadro teórico para EAD no contexto da formação de professores; descrevemos o Projeto PEAD, destacando seus principais elementos estruturantes e suas relações com o quadro teórico; relatamos a metodologia adotada para esta pesquisa; analisamos os dados obtidos e por fim tecemos as considerações finais.

\section{Educação a distância: concepções e perspectivas pedagógicas}

Para os fins do Decreto n ${ }^{0}$ 5.622, (...) "caracteriza-se a educação a distância como modalidade educacional na qual a mediação didático-pedagógica nos processos de ensino e aprendizagem ocorre com a utilização de meios e tecnologias de informação e comunicação, com estudantes e professores desenvolvendo atividades educativas em lugares ou tempos diversos. ("Decreto $\mathrm{n}^{\circ}$ 5.622”, de 19-12-2005)

As ofertas de formação na modalidade EAD, ainda que considerem o texto do Decreto 5622, apresentam-se de formas muito diversificadas, seja em relação às políticas das instituições, seja no que se refere à concepção de educação e da própria modalidade EAD, considerando os materiais e as metodologias empregadas.

Segundo Ramos (2009, p. 37), o termo concepção ${ }^{4}$ além de significar o ato de conceber mentalmente, tanto na produção de ideias como para "o produto abstrato desse processo, os conceitos", também têm significado de compreensão, de determinada maneira de ver ou apenas um ponto de vista sobre certo assunto. Os conteúdos que se articulam em tais elaborações são provenientes das relações que se estabelecem no interior de determinadas formações culturais e que refletem o movimento dialético dessas.

Para Paquette (apud BERTRAND; VALOIS, s/d, p. 66) na articulação que constitui a concepção de pedagogia aberta, a aprendizagem é, antes de tudo, uma tomada de consciência das relações que se estabelecem no ambiente educativo, com valorização da autonomia e da liberdade. Já em uma concepção de uma pedagogia fechada, as aprendizagens devem realizar-se segundo uma ordem lógica estabelecida em relação à disciplina. A primeira aprendizagem servirá de suporte à próxima aprendizagem. Essa corrente valoriza a produtividade, a racionalidade, a eficácia. Para esse autor, estamos aqui no universo do paradigma tecnológico. Esse paradigma, conforme Bertrand e Valois (s/d, p. 111), caracteriza-se, essencialmente, pela busca de uma transmissão eficaz de conhecimentos. Dentro desse quadro, o verdadeiro conhecimento é aquele que pode ser verificado empiricamente.

Bertrand e Valois (s/d, p. 31) assinalam uma concordância dos autores quanto à necessidade de mudanças que apontem para a superação do paradigma tecnológico na direção de uma ressignificação da formação de professores. Essas transformações devem ultrapassar a transmissão de saberes estáveis e fragmentados em divisões disciplinares, visando a "abertura das mentes" mediante ações-reflexões interdisciplinares, desenvolvimento do pensamento crítico e respostas criativas aos problemas cotidianos. As formações deverão considerar os princípios que regem os sistemas ecológicos, como a diversidade, o valor da cooperação e do equilíbrio e a necessidade de sustentação dentro do sistema.

Nesse contexto, o professor deixa de atuar como um transmissor de conhecimentos, passando a propor situações pedagógicas ricas em desafios que sejam capazes de provocar desequilíbrios nos esquemas do aprendiz, levando-o, em consequência, a novas formas de acomodação e assimilação. $O$ aluno realiza a aprendizagem a partir de interações, de diálogos. O professor, nessa concepção, conforme Becker (1992, p. 92), “[...] não aceita que seu aluno fique passivo ouvindo sua 


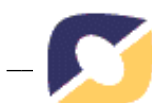

fala ou repetindo lições que consistem em dar respostas mecânicas para problemas que não assimilou”.

Ainda que muitas iniciativas em EAD adotem modelos híbridos, baseados em diferentes paradigmas, podemos identificar duas tendências pedagógicas, que norteiam as propostas de formação de professores na modalidade EAD. No Quadro 1 apresentamos uma síntese dessas duas tendências. A Tendência 1 caracteriza-se por práticas transmissivas que apontam para uma concepção pedagógica fechada, ligada ao paradigma tecnológico. Essas práticas partem da ideia que o conhecimento é uma espécie de produto de informações acumuladas dentro de uma determinada sociedade e que devem ser transmitidas e reproduzidas garantindo que os indivíduos possam desempenhar de forma competente os seus papéis sociais. Já as práticas pedagógicas centradas em comunidades de aprendizagem ou redes de aprendizagem (Tendência 2) apontam para uma concepção de conhecimento com uma visão dialética, construtivista e buscam promover a transformação, a inovação e a aprendizagem autônoma/cooperativa mediante a troca de saberes.

Quadro 1 - Quadro comparativo de s características de duas tendências nos quais se baseiam cursos de formação em Educação a Distância

\begin{tabular}{|c|c|}
\hline $\begin{array}{l}\text { Tendência } 1 \\
\text { (práticas transmissivas) }\end{array}$ & $\begin{array}{l}\text { Tendência } 2 \\
\text { (comunidades de aprendizagem) }\end{array}$ \\
\hline $\begin{array}{l}\text { Currículo rígido, estabilidade de } \\
\text { ideias, verdades, organização disciplinar. }\end{array}$ & $\begin{array}{l}\text { Currículo flexível, busca de organização } \\
\text { interdisciplinar, reconhecimento da } \\
\text { incompletude dos saberes produzidos. }\end{array}$ \\
\hline Dicotomia teoria-prática. & Busca de articulação teoria-prática. \\
\hline $\begin{array}{l}\text { Centrada em material impresso } \\
\text { para auto-aprendizagem ou no uso da } \\
\text { tecnologia dentro de modelos } \\
\text { tecnocráticos. }\end{array}$ & $\begin{array}{l}\text { Material interativo e uso da tecnologia } \\
\text { buscando uma "pedagogia da virtualidade" } \\
\text { (GADOTTI, 2004) que se opõe ao paradigma } \\
\text { individualista predominante nesse contexto. } \\
\text { Presença do professor, da interação, da } \\
\text { comunicação e do acompanhamento. Invenção } \\
\text { de outras maneiras de estar com o outro. }\end{array}$ \\
\hline $\begin{array}{l}\text { Pedagogias fechadas, } \text { ações } \\
\text { diretivas, situações } \text { de } \\
\text { aprendizagem, pouca participação do } \\
\text { professor no processo. }\end{array}$ & $\begin{array}{l}\text { Arquiteturas pedagógicas abertas (novas } \\
\text { ecologias de aprendizagem), estratégias } \\
\text { interativas e problematizadoras pela importância } \\
\text { dada à construção e a interação nos processos de } \\
\text { aprendizagem dos alunos e professores. }\end{array}$ \\
\hline $\begin{array}{l}\text { Centradas no conteúdo, leitura de } \\
\text { textos, videoconferências e exercícios, } \\
\text { definidos desde o início do curso. }\end{array}$ & $\begin{array}{l}\text { Conteúdos e atividades interativas e } \\
\text { cooperativas, propostas que são reconstruídas a } \\
\text { partir da integração do grupo, da sua } \\
\text { colaboração. }\end{array}$ \\
\hline $\begin{array}{l}\text { Avaliação } \\
\text { aprendidos (produto). }\end{array}$ & $\begin{array}{l}\text { Avaliação faz parte do processo de } \\
\text { aprendizagem, desloca o foco da avaliação das } \\
\text { performances e produtos para os processos } \\
\text { construtivos de novos instrumentos cognitivos. }\end{array}$ \\
\hline
\end{tabular}

Fonte: organizado pelas autoras com base nas perspectivas educacionais descritas em Nevado, Carvalho e Menezes (2009) e Moran (2007). 


\section{O curso de Pedagogia a distância: considerações sobre os principais elementos estruturantes}

O curso de Pedagogia a Distância da UFRGS (PEAD) foi realizado dentro do Programa Pró-Licenciatura I, que tem por objetivo a oferta de vagas em cursos de licenciatura, na modalidade a distância, em áreas da Educação Básica, onde há maior carência de professores graduados.

O PEAD, seguindo as novas diretrizes para os Cursos de Pedagogia, habilitou o/a pedagogo/a simultaneamente na docência em Educação Infantil e Anos Iniciais do Ensino Fundamental; docência em Educação de Jovens e Adultos (EJA); Gestão Escolar; docência nas matérias pedagógicas na Modalidade Normal; docência em Cursos de Educação profissional para a área de Serviços e Apoio Escolar.

O curso teve a duração de quatro anos e meio e um total de 3.300 horas, correspondentes a 213 créditos obrigatórios, destinados a atividades de discussão e atividades entre colegas, mediadas por professores, estágio supervisionado, conteúdos específicos e o Trabalho de Conclusão de Curso (TCC), além de sete créditos, envolvendo atividades complementares.

Segundo Nevado, Carvalho e Menezes (2009b) ${ }^{5}$ o curso propôs a formação de professores em uma perspectiva de redefinição da função docente e de modelos diferenciados de apropriação e construção do conhecimento, apoiada no uso intensivo da Internet. O PEAD teve o seu desenvolvimento com base em arquiteturas pedagógicas abertas que contemplam a construção cooperativa do conhecimento, a ação-reflexão, a interdisciplinaridade e a aplicação de metodologias construtivistas. Propondo uma articulação entre teoria e prática, o curso privilegiou o espaço da sala de aula das professoras-alunas (98\% do corpo discente foi formado por professoras em exercício na Educação Infantil e Anos Iniciais), como local de onde partem as reflexões que se ampliam nas teorizações para, a seguir, retornar à prática.

O currículo do PEAD apresentou uma proposta interdisciplinar, composta por nove eixos temáticos, desdobrados em interdisciplinas. A interdisciplina Seminário Integrador, desenvolvida em cada um dos semestres, pode ser compreendida como uma expressão da flexibilidade curricular proposta. O seminário não apresentava conteúdos definidos previamente, mas foi construído para atender às necessidades das interdisciplinas e da articulação entre os enfoques temáticos, desenvolvendo temáticas que contemplaram a iniciação à pesquisa, a exploração de "ferramentas intelectuais" e metodologias para apoiar e integrar o trabalho pedagógico em cada eixo.

O PEAD teve a sua proposta de trabalho planejada e acompanhada por três equipes distintas: os professores formadores, os tutores a distância e os tutores de polos. Cada equipe tinha suas funções específicas, porém trabalhavam articuladas entre si, constituindo equipes docentes integradas em cada polo.

O curso foi disponibilizado e gerenciado no ambiente ROODA, uma das plataformas virtuais da UFRGS para educação a distância (NEVADO; CARVALHO; MENEZES, 2007, p. 25), onde se realizaram, preferencialmente, as atividades de acompanhamento, comunicação, debates assíncronos, divulgação de materiais e propostas de atividades. Os registros das produções, individuais e coletivas, foram realizados em documentos textuais e hipertextuais usando espaços virtuais típicos da Web 2.0, tais como: blog, wiki, sites de compartilhamento de fotos e vídeos, além dos próprios espaços do ROODA. Para a realização de diálogos síncronos utilizaram-se as ferramentas disponíveis na Web, como o Breeze, o MSN, o Googletalk ${ }^{6}$ e o fórum do ROODA. 
As professoras-alunas eram constantemente desafiadas a apropriarem-se do conhecimento relativo ao uso de diferentes ambientes disponíveis na rede com o objetivo de qualificar a ação pedagógica para promover a inserção de atividades informatizadas, no dia a dia da ação docente, nas escolas onde trabalhavam.

\section{A investigação}

A presente investigação apresenta uma abordagem de pesquisa qualitativa, caracterizando-se como um estudo de caso. Essa abordagem permite, conforme Flick (2009) estudar experiências, interações e documentos em seu contexto de construção e de forma a poder considerar as suas particularidades.

\subsection{As Professoras-alunas do Polo de Sapiranga}

A turma do polo de Sapiranga foi composta, na maioria, por mulheres, com idade entre vinte e três e quarenta e oito anos, com carga horária semanal de trabalho docente que varia entre vinte horas e quarenta e duas horas semanais. Algumas estudantes, no momento do ingresso, não tinham nenhuma vivência relacionada com o uso do computador e, em consequência, com o uso da Internet. Mesmo entre as que possuíam computador, havia as que ainda não faziam uso dele diretamente. Quanto ao uso da Internet nas suas residências, a maioria das que dispunham desse acesso, utilizava a rede discada.

\subsubsection{Perfil das professoras-alunas que participaram da pesquisa}

Do universo de professoras-alunas vinculadas ao polo de Sapiranga, treze (20\% do número total de alunas no polo), participaram desta pesquisa. A amostra foi formada pelas professoras-alunas que atenderam ao convite, realizado via $e$-mail e/ou pessoalmente para todo o grupo, respeitando-se uma representatividade dada pela consideração de algumas características:

- Ano de ingresso no PEAD. Um grupo iniciou no segundo semestre de 2006 e o outro no primeiro semestre de 2007;

- Município de procedência. Enquanto que uma parte das professorasalunas reside/trabalha no município polo, as demais moram em municípios próximos;

- Estudo anterior em curso de Ensino Superior, modalidade presencial e modalidade a distância;

- Situação acadêmica quanto à aprovação no semestre da realização da pesquisa.

\subsection{Levantamento dos dados}

A coleta de dados foi realizada a partir de leituras dos blogs individuais nos quais as professoras-alunas registravam, sistematicamente, reflexões sobre as suas trajetórias no PEAD, dos memoriais descritivos, dos questionários de levantamento de perfil dos alunos mediante uso do SGQ ( Sistema Gestor de Questionários), bem como das respostas aos questionários, que foram complementadas, sempre que necessário, através de perguntas, em entrevistas presenciais. É importante mencionar que no caso de respostas incoerentes nas diferentes fontes pesquisadas, optou-se em fazer uso dos dados do questionário, respondido no segundo semestre de 2009. 
O levantamento dos dados enfocou: (1) as concepções das professoras-alunas relativas à EAD e as suas expectativas em relação ao curso no seu início; (2) as concepções atuais de EAD e (3) as expectativas que as professoras-alunas tinham no início do curso, a confirmação ou não dessas expectativas iniciais ao longo do mesmo e se recomendariam o PEAD a outros professores interessados em realizar um curso superior.

\section{Análise das expectativas e concepções}

As professoras-alunas responderam às questões da investigação (questões abertas) que permitiam mais de uma resposta. As respostas foram consideradas independentemente de uma ordem de importância, já que não foi solicitada essa ordenação.

Das treze professoras-alunas, conforme pode ser visto no Quadro 2, nove evidenciaram a expectativa de obter o diploma de forma mais fácil do que se frequentassem o curso presencial.

\section{Quadro 2 - Expectativas iniciais das professoras-alunas sobre o curso}

\begin{tabular}{|c|c|}
\hline Expectativas & $\begin{array}{r}\mathbf{N}^{\mathbf{0}} \\
\text { respostas }\end{array}$ \\
\hline $\begin{array}{c}\text { Curso mais fácil, menos exigência, menos esforço, menos aprendizagem } \\
\text { do que em curso presencial }\end{array}$ & 9 \\
\hline $\begin{array}{c}\text { Melhorar a prática de sala de aula e, em consequência, melhorar o } \\
\text { currículo da escola }\end{array}$ & 4 \\
\hline Obter diploma de curso superior, mesmo não acreditando na EAD & 3 \\
\hline $\begin{array}{c}\text { Realizar atividades por conta própria, com um mínimo de } \\
\text { acompanhamento por parte de professores e tutores }\end{array}$ & 2 \\
\hline Assistir a vídeos e a conferências & 2 \\
\hline Ler textos e responder a perguntas - muita teoria & 2 \\
\hline Curso de boa qualidade & 1 \\
\hline Melhorar o salário & \\
\hline
\end{tabular}

Fonte: levantamento realizado pelas autoras

As professoras-alunas pensavam que o curso teria menos exigências, que não precisariam despender muito esforço e nem ter grande comprometimento, conforme exemplificado a seguir.

Imaginava que perderia em conteúdo considerando os cursos presenciais e que a cobrança e grau de responsabilidade seria menor. (professora-aluna 5).

Essas professoras-alunas manifestaram, ainda, a expectativa de possível facilidade do curso a distância se comparado a outro presencial, crença justificada por experiências anteriores em formações na modalidade EAD de pessoas do seu convívio e delas próprias.

Acreditava que o curso seria bem simples, sem muitas exigências, na verdade seria muito fácil, não necessitaria de comprometimento. (professora-aluna 7).

Uma das professoras-alunas acrescentou que havia tomado o cuidado para não criar expectativas positivas relativas ao curso com receio de se frustrar. Outra verbalizou que contou muito, na hora de optar pelo PEAD, ver contemplada a 
possibilidade de aumentar o seu salário em decorrência de mudança de nível, previsto no Plano de Carreira dos Professores vigente no seu município.

Como estava, naquele momento, cursando Pedagogia nesta modalidade, porém de outra Instituição, não tinha um bom conceito sobre Educação a Distância. Não a percebia como formadora na verdadeira acepção da palavra, mas sim apenas como um caminho para conseguir o diploma do curso Superior. ...tomei o cuidado para não criar expectativas por medo de me frustrar. (professora-aluna 3).

Enquanto algumas professoras-alunas colocaram em segundo plano a preocupação com a qualidade do curso escolhido, outras manifestaram receio quanto a uma falta de seriedade que o mesmo poderia apresentar. Acreditavam que aprenderiam menos. Segundo Palloff e Pratt, o fato de cursos na modalidade a distância apresentarem maior facilidade é a principal crítica. "A principal crítica que se faz ao ensino online é que ele não seria tão rigoroso quanto o ensino presencial.” (PALLOFF; PRATT, 2004, p. 155).

Das treze professoras-alunas, quatro apresentaram a expectativa de melhorar a prática de sala de aula e, em consequência, melhorar o currículo. Uma delas manifestou a sua vontade de realizar a transposição didática.

[...] que este curso possa enraizar-se na prática e que eu possa irradiar tudo o que foi visto[...] a todos com quem partilho e que virão a partilhar o espaço-aula nas escolas em que trabalho. (professora-aluna 2)

Três professoras-alunas responderam que mesmo não conhecendo ou não tendo boas referências sobre EAD e não a percebendo como formadora (baixas expectativas de aprendizagem) matricularam-se no PEAD porque perceberam nele a possibilidade de obter o diploma de curso Superior, já que a Lei de Diretrizes e Bases da Educação Nacional nº 9.394, de 20 de dezembro de 1996, propôs que, após a Década da Educação (iniciada em 1997), somente seriam admitidos nas redes de ensino professores habilitados em curso superior.

Duas professoras-alunas responderam que o curso seria bom e justificaram a resposta usando como argumento o fato do mesmo ser oferecido pela UFRGS, universidade de reconhecido prestígio nos cursos presenciais. Assim, a oportunidade de cursar Pedagogia a distância sem ônus e ainda na UFRGS veio ao encontro do que desejavam. Essa valorização da Universidade foi também apontada em Silva (2010, p. 58-59), no estudo realizado sobre a transferência de trabalho no contexto da EAD.

As treze professoras-alunas, incluindo-se nesse grupo as que tinham expectativas positivas em relação ao curso, imaginavam que o curso apresentaria uma formatação baseada na apresentação de vídeos, conferências sem o acompanhamento de debates, responderiam a perguntas, haveria bastante teoria, teriam que realizar as atividades quase que exclusivamente por conta própria, contando com pouca orientação do corpo docente (professores e tutores).

Pensava que assistiríamos a vários vídeos, em aulas presenciais e expositivas, $e$ faríamos trabalhos a serem entregues impressos ou apresentados, da mesma forma que ocorrem em cursos presenciais. (professora-aluna 8). 
[...] pressupunha, de forma superficial, que não haveria tanta orientação $e$ intervenção por parte de professores da universidade, nem tanto suporte estrutural; pensava que teria de contar muito com minhas intenções e possibilidades de forma muito individual. (professora-aluna 9).

Os depoimentos das professoras-alunas mostram concepções de EAD e expectativas sobre o PEAD muito próximas ao que foi caracterizado anteriormente como Tendência Transmissiva. Esse dado aponta que todas as professoras-alunas esperavam um curso EAD no "modelo tradicional” e que a utilização desse formato, no entanto, não está diretamente relacionada à sua qualidade. É como se essa fosse a única possibilidade e que a qualidade dependesse apenas da eficiência de execução do modelo.

Essas expectativas foram antecipadas pelos organizadores do curso. Os sentimentos expressos nos depoimentos das professoras-alunas eram esperados, como se pode observar no trecho a seguir:

[...] o aspecto mais enfatizado por nós é a interação, ou seja, a comunicação e a troca de ideias, experiências e informações. [...] Temos consciência de que, no início, é difícil compreender a organização do curso, os espaços do ambiente virtual, os compromissos a assumir e, fundamentalmente, a necessidade constante de participação e troca entre tutores, colegas e professores. (NEVADO; CARVALHO; BORDAS, 2006, p. 7-8)

No Quadro 3, apresentamos as respostas das professoras-alunas relativas à concepção atual de EAD (2009) e sobre a confirmação ou não das suas expectativas com relação ao PEAD, faltando menos de três semestres para o seu término. As perguntas foram formuladas de forma aberta e permitindo mais de uma resposta.

Quadro 3 - Como as professoras-alunas concebem a EAD e o PEAD (no seu
\begin{tabular}{|c|c|}
$7^{\mathbf{o}}$ semestre) \\
\hline Como as professoras-alunas concebem a EAD e o PEAD & $\begin{array}{c}\mathbf{N}^{\mathbf{0}} \\
\text { Respostas }\end{array}$ \\
\hline Professores e tutores qualificados e presentes; interação \\
constante & 10 \\
\hline Teoria e prática andam juntas & 8 \\
\hline Integração das tecnologias & 7 \\
\hline Respeito ao ritmo pessoal & 5 \\
\hline Curso sério, comprometido com o sucesso dos alunos & 5 \\
\hline Construção do conhecimento de forma interdisciplinar & 5 \\
\hline Desenvolvimento da autonomia & 3 \\
\hline Propostas pedagógicas inovadoras e coerentes & 3 \\
\hline Diferentes formas de avaliação & 2 \\
\hline Curso exigente & 2 \\
\hline
\end{tabular}

Fonte: levantamento realizado pelas autoras

Todas as treze professoras-alunas responderam que mudaram a sua concepção de EAD e que as expectativas que possuíam no início do curso foram superadas. Atribuem a mudança no conceito referente a EAD ao trabalho desenvolvido pela equipe docente (professores e tutores) do PEAD.

Um aspecto trazido por dez professoras-alunas e considerado um diferencial no curso é a marcada presença dos professores e dos tutores. Disseram que embora estivessem a distância, podiam contar com a parceria da equipe docente, com o apoio 
das ferramentas de comunicação que foram usadas de forma adequada. Esse acompanhamento foi responsável por uma maior segurança e uma maior tranquilidade na realização das atividades acadêmicas.

Considero importante colocar que apesar do curso ser a distância, sinto os professores mais presentes do que no curso presencial. São muito mais atenciosos. Assim como os tutores, estão sempre disponíveis em algum espaço de comunicação para esclarecer dúvidas ou dar orientações. Esta 'aproximação virtual' deixa o aluno muito mais seguro e tranquilo para realizar os estudos e atividades. (professora-aluna 11)

Outro aspecto mencionado por oito professoras-alunas, refere-se à metodologia usada no PEAD que propôs o desafio da reflexão sobre a sua prática a partir das diferentes áreas do conhecimento. Um número significativo das atividades consistia em trazer a prática da sala de aula, refletir sobre a mesma, à luz da teoria, para, a partir daí, voltar à sala de aula para validar aquela prática ou então para modificá-la.

[...] Processo de formação constante onde teoria e prática andam juntas, onde se reflete sobre a própria experiência, melhorando a prática com novas informações e aprendizagens adquiridas a cada tema/conceito estudado. (professora-aluna 1)

Segundo Nevado, Carvalho e Menezes (2009a):

[...] o curso parte da experiência dos professores em serviço, construída nas suas reflexões e práticas docentes, bem como nas suas condições de vida e trabalho ao propor articular essas experiências a um aprofundamento teórico que permita a fecundação do fazer (nível de práxis) e do compreender (nível teórico).

Os mesmos autores afirmam que "um curso tem efeito nas práticas pedagógicas se realizar a convergência da teoria na prática e dessa nas práticas acadêmicas.” (NEVADO; CARVALHO; MENEZES, 2009a, p. 84).

Para algumas professoras-alunas a apropriação tecnológica foi difícil, pois no início do curso não sabiam nem ao menos ligar o computador. No entanto, hoje, além de terem utilizado a tecnologia com desenvoltura para a realização do curso propriamente dito, sentem-se preparadas para usá-la com os seus alunos, bem como fora do ambiente escolar, conforme depoimento abaixo.

Ele ficou muito além de minhas expectativas, em todas as áreas. ...Além das aprendizagens acadêmicas, criei meu blog, relacionando-me com pessoas de vários países...Cada aluno tem seu e-mail e seu Orkut, assistem músicas no YouTube ... 'dão viajadas’ no Google Earth. (professora-aluna 12)

De acordo com Nevado, Carvalho e Menezes (2009a, p. 86), o uso da tecnologia pressupõe o preparo do próprio aluno-professor para viver a experiência de mudanças na educação que ele irá proporcionar aos alunos.

As professoras-alunas reconheceram a articulação de vários assuntos, estudados sob a perspectiva de mais de uma área do conhecimento, como um ponto forte do curso, conforme o exemplo a seguir.

[...] disciplinas que trabalham juntas, com interdisciplinaridade, desenvolvendo os mesmos conceitos, cada uma na sua especialidade. (professora-aluna 3) 
Segundo Nevado, Carvalho e Menezes (2009a, p. 93), os currículos funcionam metaforicamente como mapas ao mostrar diferentes direções para se realizar algo, entretanto, cabe ao sujeito escolher e determinar o lugar para onde ir e quais caminhos percorrer. Pode-se percorrê-los individual ou coletivamente; ambas as formas são necessárias mesmo dentro de uma comunidade de aprendizagem.

A proposta e a coerência pedagógica, incluindo-se a avaliação no processo, também foram citadas pelas professoras-alunas como aspectos importantes do curso.

Encontrei uma coerência de metodologias, uma coerência pedagógica, originada de uma visão educacional. Uma visão que defende a democratização da educação, a luta pela garantia dos direitos sociais, que entende a educação como um dos centros de mudança social e individual, a partir de propostas que elevam o patamar de moralidade e conhecimento de todos os educandos. Essa coerência passa pelo caráter amoroso e envolvimento bastante pessoal de toda a equipe com todas as professorasalunas e aluno. (professora-aluna 4)

O depoimento a seguir aponta evidências de que houve a contemplação das expectativas, de forma favorável.

Curso de qualidade que integra tecnologias e propostas pedagógicas inovadoras com foco na aprendizagem, onde o ritmo pessoal é respeitado, a interação em grupos é estimulada e diferentes formas de avaliação são contempladas. (professora-aluna 13)

As professoras-alunas afirmaram que, ao final do curso, perceberam-se diferentes em todas as áreas, em especial na esfera pessoal e na profissional. Observaram que as suas aulas ficaram melhores, sentiram-se mais independentes, criativas, ativas, melhor aceitas por seus pares. Verificaram que as pessoas ao seu redor notaram as mudanças e que as desconfianças de antes foram dissipadas, pois perguntaram sobre como podiam ter acesso ao mesmo curso, conforme depoimentos abaixo. Segundo Palloff e Pratt, "Ao criar tarefas e trabalhos que são desafiadores e que conduzem os alunos a altos padrões, podemos criar cursos online que suplantam a experiência presencial.” (PALLOFF; PRATT, 2004, p. 155).

Nesses seis semestres já cursados, poderia dizer que me tornei outra pessoa, muito mais independente, criativa e ativa. Também poderia dizer que era uma pessoa antes do $P E A D$, com ideais e ideias limitadas e outra hoje, com um caminho infinito a ser trilhado e conhecido. (professora-aluna 10)

Certamente muito preconceito se desfez durante este curso, pois quando iniciei muitos me diziam que não eram bons estes cursos a distância e eu sempre contestando. Hoje algumas dessas pessoas que perceberam minhas mudanças e melhorias, minha paixão pelo curso, vem e me perguntam como está o curso, pois gostam dos projetos que desenvolvo, da minha prática de sala de aula, da maneira como trato meus alunos, gostam quando os convidamos para apreciar os nossos trabalhos.(professora-aluna 3)

Nessa mesma direção, uma professora-aluna destacou que o curso promoveu a autoestima e a ter esperança de construir um mundo melhor. 
É um curso de excelência, onde se aprende a ser um professor melhor, onde se aprende a compreender melhor alunos e alunas, que nos eleva a autoestima, que nos dá esperança de conseguirmos colaborar para a construção de um mundo melhor, a partir de indivíduos mais cooperativos, que se aprende tecnologia, que vale para qualquer outra área, que se aprende a aprender. (professora-aluna 4)

Algumas professoras-alunas lamentaram o fato do curso estar chegando ao seu término, pois o perceberam como um guia de suas práticas.

Sinceramente? Já estou lamentando que esteja tão perto de terminar. Tudo que estudamos está tão conectado com os desafios de sala de aula que o curso, para mim, funciona, também, como um porto seguro ou um farol que guia a minha prática. Desta forma, posso dizer com segurança que o curso superou e em muito minhas expectativas. (professora-aluna 13)

Quanto às respostas à questão “você recomendaria o curso a outras pessoas?”, todas as professoras-alunas responderam que sim. Como argumentos destacaram que o curso é confiável, sério, comprometido com o crescimento do aluno e que as interdisciplinas são planejadas com responsabilidade. Além disso, há ocorrência da ação/reflexão, respeito ao ritmo individual do aluno, estímulo à interação grupal, utilização de ambiente de aprendizagem de fácil acesso, proximidade virtual entre os protagonistas, contato com pessoas de diferentes realidades, bem como proposta de atividades variadas, ora individuais ora em grupos.

O depoimento a seguir exemplifica alguns dos argumentos que utilizariam para convencer um provável candidato a realizar o PEAD:

Eu perguntaria: Você deseja um diploma ou deseja qualificar-se? Se respondesse um diploma.... Se respondesse qualificar-se, diria: Corre para a UFRGS, porque o curso vai te fazer refletir sobre tua prática, vai oferecer embasamento teórico de fundamento e o aliará a tua vivência de sala de aula, de modo que tudo que tu vais ver será significativo e, por isto mesmo, se tornará de fácil compreensão, logo, também de fácil aplicação... Porque encontrará professores qualificados, suporte tecnológico, aprenderá a socializar ideias, compartilhar conhecimentos, respeitar posicionamentos, pesquisar, cooperar... tu te tornarás um educador muito melhor. Mais qualificado, mais questionador, mais reflexivo, mais ativo, mais consciente. (professora-aluna 1)

Assim como na questão anterior, as respostas das professoras-alunas evidenciaram que elas perceberam no curso as características de uma proposta pedagógica apoiada no conceito de redes colaborativas e que consideraram esta abordagem facilitadora de suas aprendizagens.

\section{Considerações finais}

O estudo evidenciou que as treze professoras-alunas participantes da pesquisa tiveram as suas expectativas superadas positivamente. Essa superação, explicitada nas manifestações das professoras-alunas, revelou que inclusive aquelas que iniciaram o curso com boas expectativas viram-se surpreendidas, tanto do ponto de vista pedagógico quanto da apropriação da tecnologia.

As expectativas de que o curso seria simplificado, instrucionista ${ }^{7}$ e mais fácil dos que os presenciais aos poucos foram sendo substituídas por novas percepções. 
Dentre essas podemos destacar: (1) a percepção de que o curso apresenta características que integram tecnologias e propostas pedagógicas inovadoras com foco na aprendizagem, (2) o respeito ao ritmo de aprendizagem, (3) o incentivo à interação e a formação de redes de aprendizagem, (4) a avaliação diferenciada e (5) a presença constante de professores e tutores, em modo face a face ou mediado, para contribuir na solução de dificuldades.

Os resultados da pesquisa apontaram para o fato de que as professoras-alunas, gradualmente, tomaram consciência da proposta pedagógica (Projeto Político Pedagógico) e consideraram que o PEAD/UFRGS efetivou o modelo de aprendizagem em rede, deslocando o centro do processo de construção de conhecimento do professor para o grupo (que participa, debate, pesquisa, interage, cria), na perspectiva de superar as fragmentações e dicotomias entre o projeto pedagógico e a prática no curso.

\footnotetext{
${ }^{1}$ Entre outras iniciativas, podemos citar a Unirede, o CEDERJ, o projeto Veredas.

${ }^{2}$ O Pró-licenciatura Fase I, instituído pela Chamada Pública SEED/MEC nº 01/2004, teve início em 2004, e o público-alvo são os alunos egressos do Ensino Médio, aprovados no vestibular realizado pelas IES participantes.

${ }^{3}$ Optamos pelo uso do termo professoras-alunas em decorrência do curso contar com 98\% de alunas.

4 “[...] as concepções, crenças e atitudes docentes se expressam e se caracterizam por um corpo de conceitos e valores organizados em teorias, explícitas e latentes, evidenciadas pelos modos de agir do sujeito. Assim, de acordo com seu funcionamento, as concepções podem ser transformadas pelo contexto imediato que as provocam, o que implica dizer que podem ser reconstruídas com base nos saberes acumulados pelo indivíduo. Trata-se, neste caso, de fenômeno relativo à evolução de concepções de crenças, de pensamento, refletindo seu caráter de dinamicidade.” (LIMA, 2003, p. 30).

${ }^{5}$ http://senaedpedagogiaead.wordpress.com

${ }^{6}$ O Breeze, o MSN, o Googletalk são sistemas de comunicação Web que oferecem facilidades para a interação síncrona.

${ }^{7} \mathrm{Na}$ abordagem instrucionista o computador é usado como meio para transmitir a informação ao aluno, geralmente sob a forma de tutoriais, exercício e prática. (VALENTE, 1993)
}

\section{Referências}

BECKER, F.. O que é Construtivismo? 1992. Disponível em: http://www.crmariocovas.sp.gov.br/pdf/ideias_20_p087-093_c.pdf . Acessado em 14 de novembro de 2012.

BERTRAND, Y. \& VALOIS, P. Paradigmas educacionais: escolas e sociedades. Instituto Piaget. Portugal (s/d).

CARVALHO, M.J.; NEVADO, R.A.; BORDAS, M.C. Guia do aluno: Curso de Licenciatura em Pedagogia a Distância: Anos Iniciais do Ensino Fundamental. Faculdade de Educação (FACED). Porto Alegre, 2006.

CARVALHO, M.J.; NEVADO, R.A.; BORDAS, M.C. Guia do tutor. Curso de Licenciatura em Pedagogia a Distância: Anos Iniciais do Ensino Fundamental. Faculdade de Educação (FACED). Porto Alegre, 2006.

FLICK, U. Desenho da pesquisa qualitativa. Coleção Pesquisa Qualitativa. Artmed, Porto Alegre, 2009.

GADOTTI, M.; ROMÃO, J. E. Prefácio. In: Educação em rede: uma visão emancipadora. São Paulo: Cortez: Instituto Paulo Freire, 2004. 
MEC. Referenciais de Qualidade para Educação Superior a Distância. 2007. Disponível em http://portal.mec.gov.br/seed/arquivos/pdf/legislacao/refead1.pdf Acesso em: 20 de agosto 2009

MORAN, J. M. O que é um bom curso a distância? 2002. Disponível em http://www.eca.usp.br/prof/moran/bom_curso.htm Acessado em 14 de novembro de 2012.

MORAN, J. M., 2007. Os Modelos educacionais na aprendizagem. Disponível em http://www.eca.usp.br/prof/moran/modelos.htm. Acesso em 14 de novembro de 2009.

NEVADO, R. Espaços interativos de construção de possíveis: uma nova modalidade de formação de professores. PGIE/UFRGS, 2001. 244p. Tese de Doutorado.

NEVADO, R.A.; CARVALHO M.J.; MENEZES, C.S. Aprendizagem em rede na Educação a Distância: estudos e recursos para formação de professores. Porto Alegre: Ricardo Lenz, 2007.

NEVADO, R.A.; CARVALHO M.J.; MENEZES, C.S. Metarreflexão e a construção da (trans)formação permanente: estudo no âmbito de um curso de Pedagogia a Distância. In: VALENTE, J. A. e BUSTAMANTE, S. B. V. - organizadores. Educação a Distância - Prática e Formação do Profissional Reflexivo. São Paulo, 2009a, p. 83 a 108.

NEVADO, R.A.; CARVALHO M.J.; MENEZES, C.S. Arquiteturas pedagógicas no PEAD. Disponível em http://senaedpedagogiaead.wordpress.com/. 2009b.

PALLOFF, Rena M. e PRATT, Keith. O aluno virtual. Porto Alegre: Artmed, 2004.

PETERS, Otto. Didática do ensino a distância. São Leopoldo: UNISINOS, 2001.

PRETI, O. A Formação do professor na modalidade a distância: (DES) construindo metanarrativas e metáforas. In PRETI, O. (org) Educação a Distância: sobre discursos e práticas. Brasília: Liber Livro Editora, 2005.

SANCHEZ, Fábio (coordenador). Anuário brasileiro estatístico de Educação Aberta e a Distância. 4. Ed. São Paulo: Instituto Monitor, 2008.

SILVA. I. C. Presença virtual: um estudo sobre a transferência em contexto de Educação a Distância. Universidade Federal do Rio Grande do Sul, 2010. 149p. Tese de doutorado.

VALENTE, JA Computadores e conhecimento: repensando a educação. Campinas: Gráfica da UNICAMP, 1993. 